\title{
The reanalysis of biogeography of the Asian tree frog, Rhacophorus (Anura: Rhacophoridae): Geographic shifts and climatic change influenced the dispersal process and diversification
}

Tao Pan ${ }^{1}$, Yanan Zhang ${ }^{1}$, Hui Wang ${ }^{1}$, Jun Wu ${ }^{2}$, Xing Kang ${ }^{1}$, Lifu Qian ${ }^{1}$, Jinyun Chen ${ }^{3}$, Dingqi Rao ${ }^{4}$, Jianping Jiang ${ }^{5}$, Baowei Zhang ${ }^{\text {Corresp. } 1,6}$

\footnotetext{
1 Anhui Key Laboratory of Eco-engineering and Bio-technique, School of Life Sciences, Anhui University, Hefei, Anhui Province, China

2 Ministry of Environmental Protection, Nanjing Institute of Environmental Sciences, Nanjing, Jiangsu, China

3 Department of Life Science, Huainan Normal University, Huainan, Anhui, China

4 Kunming Institute of Zoology, Chinese Academy of Sciences, Kunming, Yunnan, China

5 Chengdu Institute of Biology, Chinese Academy of Sciences, Chengdu, China

${ }^{6}$ School of Biosciences, Cardiff University, Cardiff, United Kingdom
}

Corresponding Author: Baowei Zhang

Email address: zhangbw@ahu.edu.cn

Rapid uplifts of the Tibetan Plateau and climate change in Asia are thought to have profoundly modulated the diversification of most of the species distributed throughout Asia. The ranoid tree frog genus Rhacophorus, the largest genus in the Rhacophoridae, is widely distributed in Asia and especially speciose in the areas south and east of the Tibetan Plateau. Here, we infer phylogenetic relationships among species and estimate divergence times, asking whether the spatiotemporal characteristics of diversification within Rhacophorus were related to rapid uplifts of the Tibetan Plateau and concomitant climate change. Phylogenetic analysis recovered distinct lineage structures in Rhacophorus, which indicated a clear distribution pattern from Southeast Asia toward East Asia and India. Molecular dating suggests that the first split within the genus date back to the Middle Oligocene (approx. $30 \mathrm{Ma}$ ). The Rhacophorus lineage through time (LTT) showed that there were periods of increased speciation rate: 14 - $12 \mathrm{Ma}$ and 10 - $4 \mathrm{Ma}$. In addition, ancestral area reconstructions supported Southeast Asia as the ancestral area of Rhacophorus. According to results of the molecular dating, ancestral area reconstructions and LTT, we think the geographic shifts, the staged rapid rises of the Tibetan Plateau with parallel climatic changes and reinforcement of the Asian monsoons (15 Ma, $8 \mathrm{Ma}$ and $4-3$ Ma), possibly prompted a burst of diversification in Rhacophorus. 
1 The reanalysis of biogeography of the Asian tree frog, Rhacophorus (Anura:

2 Rhacophoridae): geographic shifts and climatic change influenced the

3 dispersal process and diversification

4

5 Tao Pan ${ }^{1 \uparrow}$, Yanan Zhang ${ }^{1 \uparrow}$, Hui Wang ${ }^{1}$, Jun $\mathrm{Wu}^{2}$, Xing Kang ${ }^{1}$, Lifu Qian ${ }^{1}$, Jinyun $\mathrm{Chen}^{3}$, Dingqi

$6 \mathrm{Rao}^{4}$, Jianping Jiang 5 , and Baowei Zhang ${ }^{1,6 *}$

7

$8{ }^{1}$ Anhui Key Laboratory of Eco-engineering and Bio-technique, School of Life Sciences, Anhui

9 University, Hefei, Anhui, China

$10{ }^{2}$ Ministry of Environmental Protection, Nanjing Institute of Environmental Sciences, Nanjing,

11 Jiangsu, China

$12{ }^{3}$ Department of Life Science, Huainan Normal University, Huainan, Anhui, China

$13{ }^{4}$ Kunming Institute of Zoology, Chinese Academy of Sciences, Kunming,Yunnan, China

$14{ }^{5}$ Chengdu Institute of Biology, Chinese Academy of Sciences, Chengdu,Sichuan, China

${ }^{6}$ School of Biosciences, Cardiff University, Cardiff, CF103AX, United Kingdom.

17 These authors contributed equally to this work.

$18 *$ Corresponding author

19 E-mail address: zhangbw@ahu.edu.cn (Baowei Zhang) 


\section{ABSTRACT}

Rapid uplifts of the Tibetan Plateau and climate change in Asia are thought to have profoundly modulated the diversification of most of the species distributed throughout Asia. The ranoid tree frog genus Rhacophorus, the largest genus in the Rhacophoridae, is widely distributed in Asia and especially speciose in the areas south and east of the Tibetan Plateau. Here, we infer phylogenetic relationships among species and estimate divergence times, asking whether the spatiotemporal characteristics of diversification within Rhacophorus were related to rapid uplifts of the Tibetan Plateau and concomitant climate change. Phylogenetic analysis recovered distinct lineage structures in Rhacophorus, which indicated a clear distribution pattern from Southeast Asia toward East Asia and India. Molecular dating suggests that the first split within the genus date back to the Middle Oligocene (approx. $30 \mathrm{Ma}$ ). The Rhacophorus lineage through time (LTT) showed that there were periods of increased speciation rate: $14-12 \mathrm{Ma}$ and 10 - 4 Ma. In addition, ancestral area reconstructions supported Southeast Asia as the ancestral area of Rhacophorus. According to results of the molecular dating, ancestral area reconstructions and LTT, we think the geographic shifts, the staged rapid rises of the Tibetan Plateau with parallel climatic changes and reinforcement of the Asian monsoons (15 Ma, $8 \mathrm{Ma}$ and $4-3 \mathrm{Ma}$ ), possibly prompted a burst of diversification in Rhacophorus.

\section{INTRODUCTION}

Abiotic factors like climatic and tectonic events, and biotic factors like inter- or intraspecific 
interactions, competition and predation, may be the predominant driving factors during the evolution and diversification of organisms (Antonelli \& Sanmartín 2011; Benton 2009). These factors can also affect the diversification at different temporal and geographical scales (Benton 2009). Understanding the processes of diversification and which factors have driven the evolution and diversification of organisms, may help guide prioritization in conservation and forecast the population demography under future climate conditions (Avise 2000; Frankham et al. 2002). It had been shown that orogenic activity during recent geological history was linked to the formation of hotspots of biodiversity (Myers et al. 2000). Consequently, the study of the origin and evolution of biodiversity in mountain systems has experienced a growing scientific interest (Klaus et al. 2016; van der Meijden et al. 2007; Zhang et al. 2006). In Asia, the uplift of the Tibetan Plateau was the most intense orogenic movement leading to the formation of several biomes (Favre et al. 2015; Klaus et al. 2016; Myers et al. 2000; Yang et al. 2009). Therefore, research has focused on the uplift of the Tibetan Plateau, based on a temporal (molecular dating) and spatial (biogeographic) framework, which may have triggered a series of evolutionary changes in different biological groups (Klaus et al. 2016), such as in plants (Gao et al. 2013; Jabbour \& Renner 2012; Tu et al. 2010; Wang et al. 2009), birds (Lei et al. 2014; Tietze \& Borthakur 2012; Tietze et al. 2013), mammals (Deng et al. 2011) and amphibians (Che et al. 2010; Guo et al. 2011; Li et al. 2013; Vijayakumar et al. 2016; Zhang et al. 2006).

57 The ranoid treefrog genus, Rhacophorus, is the largest genus in the Rhacophoridae, currently containing 88 species (Frost 2016), which are widely distributed across India, China, Japan, mainland South-east Asia, the Greater Sunda Islands and the Philippines (Frost 2016). A 
60

61

62

previous study disclosed that Rhacophoridae underwent an early dispersal from India to Asia between 46 and $57 \mathrm{Ma}$, that a transient faunal exchange ceased during the Middle Eocene, and a subsequent increase of Rhacophorid dispersal events between Asia and the Indian subcontinent during the Oligocene that continued until the Middle Miocene (Li et al. 2013). Uplift of the Tibetan Plateau and a series of climatic and environmental changes led to many speciation events on a very large scale (Favre et al. 2015; Myers et al. 2000; Yang et al. 2009). Rhacophorus taxa are widely distributed across the areas around the Tibetan Plateau, according to previous study (Li et al. 2013), the speciation process in this genus may be linked to the uplift of Tibetan Plateau during the Miocene and Pliocene.

To gain a better understanding of the diversification processes in biomes around the Tibetan Plateau, we herein provide a historical biogeographic pattern of Rhacophorus. In the present study, we collected all the sequences datasets of Asian Rhacophorus that have been reported in addition to newly sequenced DNA from Rhacophorus specimens collected from the Dabie Mountains in Anhui, China. We infer the phylogenetic relationships within the genus and estimate the divergence times. Further, the correlation between diversification events within Rhacophorus and the geographic shifts in the Tibetan Plateau are explored.

\section{MATERIALS AND METHODS}

\section{Ethical Statement}


79

80

81

82

83

84

85

amphibians of Dabie mountains. This investigation project and the sample collection were approved by Anhui Tianma National Nature Reserve, Anhui Province, China. The relevant document of field permit was provided in the supplementary material.

\section{Data Collection}

For the phylogenetic analyses, sequences of about half the species of Rhacophorus were used in combination with sequences of two outgroup species, Polypedates megacephalus (Rhacophoridae, Polypedates) and Spinomantis peraccae (Mantellidae, Spinomantis) (Li et al. 2013; Li et al. 2012a; Li et al. 2012b). Sequence data were obtained from GenBank (the GenBank Accession numbers are given in Table S1). In total, there were 149 individuals of 57 species of Rhacophorus involved (Fig. 1 and Table S1). All the taxonomic revisions within Rhacophorus were follow previous studies (Biju et al. 2013; Li et al. 2013; Orlov et al. 2012).

\section{Sampling, DNA Extraction, PCR Amplification, and Sequencing}

Between 2012 to 2015, nine specimens of $R$. zhoukaiyae were collected from the Dabie Mountains, China (Pan et al. 2017). Muscle tissue from each individual was sampled and preserved in $100 \%$ ethanol for DNA extraction. Total DNA was extracted from the samples using a standard proteinase K/phenol-chloroform protocol (Sambrook et al. 1989). An EasyPure PCR Purification Kit (TransGene) was used to purify the DNA extractions. The sequences of $12 \mathrm{~S}$ and 16S ribosome RNA (rRNA) of $R$. zhoukaiyae were collected from Pan et al. (2017). In 
98

99

100

101

102

103

104

105

106

107

108

109

110

111

112

113

114

115

116

117

addition, we also amplified and sequenced five nuclear gene fragments with the indicated primer pairs (Table S2), including brain-derived neurotrophic factor (BDNF), proopiomelanocortin (POMC), recombination activating gene 1 (RAG-1), rhodopsin exon 1 (RHOD) and tyrosinase exon 1 (TYR) (Bossuyt \& Milinkovitch 2000; Li et al. 2009; van der Meijden et al. 2007; Vieites et al. 2007; Wiens et al. 2005). Polymerase chain reactions (PCR) were performed using a reaction mixture $(25 \mu \mathrm{L})$ containing $1 \mu \mathrm{L}$ genomic DNA (concentration $10-50 \mathrm{ng} / \mu \mathrm{L}$ ), $2.5 \mu \mathrm{L}$ $10 \times$ buffer, $1 \mu \mathrm{L}$ of $2.5 \mathrm{mM} \mathrm{MgSO} 4,2 \mu \mathrm{L}$ of $2 \mathrm{mM}$ dNTPs, $1 \mathrm{U}$ Taq polymerase (Meridian Bioscience, Singapore) and $0.3 \mathrm{mM}$ of each of the primers. Pure molecular biology grade water was added to reach the appropriate volume. The amplification protocol included an initial denaturation step of $95^{\circ} \mathrm{C}$ for $5 \mathrm{~min}$; this was followed by 32 cycles of denaturation at $95^{\circ} \mathrm{C}$ for $30 \mathrm{~s}$, primer annealing at $51^{\circ} \mathrm{C}-57^{\circ} \mathrm{C}$ for $30 \mathrm{~s}$, and an extension at $72^{\circ} \mathrm{C}$ for $40 \mathrm{~s}-80 \mathrm{~s}$, with a final extension at $72^{\circ} \mathrm{C}$ for $10 \mathrm{~min}$. PCR products were purified using an EasyPure PCR Purification Kit (TransGene) and sequenced using previous primers and the BigDye Terminator v3.0 Ready Reaction Cycle Sequencing Kit (Applied Biosystems) following the manufacturer's instructions on an ABI Prism 3730 automated sequencer. All the sequences obtained in this study were deposited into GenBank (Table S1). For the analyses, the sequences were trimmed to match data downloaded from GenBank, then all the sequences were aligned automatically using Clustal X version 1.83 (Thompson et al. 1997), followed by visual confirmation and manual adjustments. Nucleotide sites with ambiguous alignments were removed from the analyses, and gaps were analyzed as missing data. 
118

119

120

121

122

123

124

126

127

128

129

130

131

132

133

134

135

\section{Phylogenetic Analyses}

Two different datasets were generated for the different analyses. Dataset 1 was used for a phylogenetic analysis of Rhacophorus by Maximum Likelihood (ML) and Bayesian methods, was comprised of the $12 \mathrm{~S}$ and $16 \mathrm{~S}$ rRNA gene together with the complete t-RNA for the valine sequence of the Rhacophorus species and the outgroups (Table S1). Dataset 2 contained more genes (12S, 16S, Val, BDNF, POMC, RAG-1, RHOD, TYR) of more individual and species than Dataset 1 (Table S1). However, it was only used to calculate a Bayesian consensus tree. The best-fit model of evolution was calculated by MrModeltest $1.0 \mathrm{~b}$ under the AIC criterion (Nylander 2003). ML analyses were performed in RAxML version 8 (Stamatakis 2014) and a general time reversible model of nucleotide substitution under the Gamma model of rate heterogeneity (i.e., GTRCAT). Support for the internal branches for the best-scoring tree was evaluated via the bootstrap test with 1,000 iterations. A Bayesian inference of phylogeny was performed using the MrBayes 3.1.2 software program (Huelsenbeck \& Ronquist 2005), using the best-fit substitution model. Two Markov Chain Monte Carlo (MCMC) models were run to provide additional confirmation of the convergence of posterior probability distributions. Analyses were run for 3,000,000 generations. Chains were sampled every 1000 generations. The first $25 \%$ of the total trees were discarded as "burn-in" and the remaining trees were used to generate a majority-rule consensus tree and to calculate Bayesian posterior probabilities. 
136

137

138

139

140

141

142

143

144

145

146

147

148

149

150

151

152

153

154

\section{Divergence Time Analyses}

To estimate divergence times of Rhacophorus, we applied a Bayesian MCMC method with mitochondrial genes (Dataset 1), which employs a relaxed molecular clock approach, as implemented in BEAST 1.7.4 (Drummond et al. 2012). We assumed a relaxed uncorrelated log normal model of lineage variation and a Yule Process prior to the branching rates based on the GTR + I + G model as recommended by MrModeltest 1.0 b (Nylander 2003). Four replicates were run for $10,000,000$ generations with tree and parameter sampling every 1,000 generations. The first $25 \%$ of samples were discarded as burn-in. All parameters were assessed by visual inspection using Tracer v. 1.5 (Rambaut \& Drummond 2007). The tree was generated and visualized with TreeAnnotator v. 1.6.1 (Rambaut \& Drummond 2010) and FigTree v. 1.3.1 (Rambaut 2009), respectively. Calibration points were taken from Li et al. (2013) (Table 1). In addition, to visualizing the temporal accumulation of species, a log-transformed lineage-throughtime (LTT) (Nee et al. 1994) plot was constructed and compared with the null distribution for the LTT line simulated under the empirical pure-birth model. For visualizing diversification rate changes, we plotted the number of newly appearing species against the fixed time intervals of 2 million years (Ma) (Venditti et al. 2010).

\section{Ancestral Area Reconstructions}

Ancestral area reconstructions were inferred by the program RASP 3.2 (Yu et al. 2015) for speciational evolution in phylogenetic trees, using the Bayesian Binary MCMC (BBM) method 
155 (Ronquist \& Huelsenbeck 2003) and the statistical dispersal-vicariance method (S-DIVA) (Yu et

156 al. 2010). To reconstruct ancestral areas on the basis of the topography, the distributional range

157 of Asian Rhacophorus was divided into four regions, W, X, Y and Z (Fig. 2). W represents

158 Southeast Asia, including the Indochinese Peninsula, Sundaland and the south margin of the

159 Tibetan Plateau, $X$ contains the Hengduan mountains and the mountains around the Sichuan

160 Basin, Y refers to South China and Japan and Z represents India (Fig. 2). The tree data sets and

161 the condensed tree were generated by BEAST 1.7.4 (Drummond et al. 2012). The distribution of

162 each species was collected from http://maps.iucnredlist.org. For all analyses, the maximum

163 number of ancestral areas at each node was constrained to three. The frequencies of an ancestral

164 range at a node were averaged over all trees and each alternative ancestral range at a node was

165 weighted by the frequency of occurrence for the node.

166

167 RESULTS

168 Molecular Phylogenetic Analyses

The aligned mtDNA gene fragments from Rhacophorus consisted of 1935 bp nucleotide positions before trimming (Dataset 1). After trimming, 1851 nucleotide positions were retained

171 for genealogical reconstructions. The fragments contained 934 constant and 917 potentially

172 phylogenetically informative characters. The ML or BI phylogenetic approaches based on

173 Dataset 1 resulted in virtually identical topology, and all terminal clades obtained relatively high- 
174 supporting values (Fig. S1). The genus Rhacophorus was supported as monophyletic containing 175 four major clades (Fig. S1). For further probing of the dispersal process and diversification of the 176 Asian tree frog, the molecular dating and ancestral area reconstructions were carried out. The 177 phylogenetic tree, collected from the molecular dating, showed three distinct clades (A, B and C) 178 in the genus of Rhacophorus (Fig. 2). There were some difference in the species distribution

179 180 181 182 183 184 185 186 187

areas among the three clades. Species in clade A were mostly distributed in Southeast Asia and East Asia, species in Clade B were distributed in Southeast Asia and India, and species in lineage C only found in Southeast Asia. Clade A contained six groups, A1 to A6 (Fig. 2). The phylogenetic tree, based on Dataset 2, was largely consistent with the results from Dataset 1 (Fig. S2). However, there were some minor differences between them, such as the polyphyletic of clade $\mathrm{B}$ and $\mathrm{C}$ in Fig. S2. But, generally, it did not affect the results of ancestral area reconstructions of Rhacophorus.

\section{Molecular Dating, Ancestral Area Reconstructions and Lineage Through Time}

Dating analyses based on Dataset 1 suggested that the most recent common ancestor (MRCA) of Rhacophorus dates back to 29.51Ma (median value; 95\% of the highest posterior density $[\mathrm{HPD}]=25.00-34.07 \mathrm{Ma}$ ) (Table 1 and Fig. 3). The MRCA of Clade A and Clade B was estimated at 27.38Ma (95\% HPD = 22.44 - 32.17 Ma). The MRCA of Clade A was 21.56 Ma $(95 \% \mathrm{HPD}=17.92-25.22 \mathrm{Ma})$ and the MRCA of Clade B was $26.73 \mathrm{Ma}(95 \% \mathrm{HPD}=21.56-$ $31.83 \mathrm{Ma})$. 
some minor differences (Fig. 2). All analyses supported Southeast Asia (Area W, Fig. 2) as the

196

197

198

199

200

201

202

203

204

205

206

207

208

209

210

211

21 ancestral area of Rhacophorus and most speciation events were attributed to dispersal. The empirical LTT plot of Rhacophorus showed that, after a lengthy period of constant diversification, the diversification rate of the genus had increased during the middle Pliocene. The cumulative curve of species-birth per time interval showed that the diversification of Rhacophorus fluctuated through time, especially during 14-12 Ma and 10 - 4 Ma (Fig. 4).

\section{DISCUSSION}

\section{The Dispersal Process of Rhacophorus and Its Spread toward East Asia and India}

Previous studies have indicated that the diversification of Rhacophoridae was closely linked to the India-Asia collision (57 Ma - $35 \mathrm{Ma}$ ) (Li et al. 2013). Southeastern Asia houses three globally significant hot spots divided by sharp, yet porous biogeographic boundaries (Evans et al. 2003; Favre et al. 2015; Schmitt et al. 1995; Wallace 1860). Studies have shown that the dynamics of the formation of biodiversity in Southeastern Asia is assumed to be interrelated with many geological events and a unique climatic history,. Events such as the continuing processes of volcanic uplift and the emergence of many new islands in Indo-Australian Archipelago during the Miocene-Pliocene (Fig. 3iii) (Esselstyn et al. 2009; Hall 1996; Hall 1998; Hall 2002; Lohman

211 et al. 2011), the rapid uplifts of the Tibetan Plateau (Shi et al. 1999), repeated sea level 212 fluctuations during the Pleistocene (Bird et al. 2005; Esselstyn et al. 2009; Hall 1998; Heaney 
213 1985; Heaney 1986; Jansa et al. 2006; Voris 2000) and the onset of the Asian monsoon system

214 (An et al. 2001; Qiang et al. 2001; Sun \& Wang 2005; Zhisheng et al. 2001). Many 215 phylogeographical studies of plants and animals support this assumption (Deng et al. 2011;

216 Klaus et al. 2016; Shi et al. 1999), such as those on Lilium (Gao et al. 2013), Delphinieae

217 (Jabbour \& Renner 2012), Hyoscyameae (Tu et al. 2010), Mandragoreae (Tu et al. 2010), 218 Saussurea (Wang et al. 2009), birds (Lei et al. 2014; Tietze \& Borthakur 2012; Tietze et al. 2013;

219 Yang et al. 2009), Hynobiidae (Zhang et al. 2006), lizards (Guo et al. 2011) and Spiny Frogs

220 (Che et al. 2010), so the diversification and speciation in Rhacophorus may also be related to the

221 special geological formations and the climatic history.

222 The phylogenetic analysis shows that Rhacophorus is composed of multiple lineages. In the 223 phylogenetic tree with timescale, calculated by BEAST, Rhacophorus is composed of three 224 major clades, A, B and C (Fig. 2). Among these clades, Clade C was the basal branch of 225 Rhacophorus, which contained ten species from Southeast Asia, and the age of the MRCA of 226 Rhacophorus was estimated at 29.51 Ma (i.e., 95\% CI, 25 - 34.07 Ma, Fig. 2 and Table 1). The 227 MRCA of Clades B and Clade A was 27.38 Ma (95\% CI, 22.44 Ma - 32.17 Ma) during the 228 Oligocene (Fig. 2, Table 1). The members of Clades A and B are mainly distributed in the south 229 of the Tibetan Plateau margin, India and Eastern Asia (Fig. 1). Clade A contained six groups 230 which were distributed in three areas: Southeast Asia (group A1), the south of the Tibetan 231 Plateau margin (group A2) and an Eastern Asia (group A3 to A6) (Fig. 1, 2). The MRCA of 232 Clade A occurred 21.56 Ma ago (95\% CI, 17.92 - 25.22 Ma; Fig. 2) and the time of the split of 233 different groups was estimated at 14.09 Ma (A2 vs A3 A6, 95\% CI, 10.96 - 17.41 Ma), 11.39 
234 Ma (A3 vs A4 A6, 95\% CI, $8.89-14.16 \mathrm{Ma}$ ), $8.56 \mathrm{Ma}$ (A4 vs A5 A6, 95\% CI, 6.43-10.88

$235 \mathrm{Ma}$ ) and 5.33 Ma (A5 vs A6, 95\% CI, 3.92 - 6.99 Ma) respectively (Table 1). In addition, the

236 LTT plot analysis indicated an increased diversification rate during two periods (14 - $12 \mathrm{Ma}$ and

$23710-4 \mathrm{Ma})$ (Fig. 4). Basically, the above mentioned phylogeographical information reflected the

238

239

240

241

242

243

244

245

246

247

248

249

250

251

252

253

254

trend of diversification and the speciation process. Obviously, the distribution of these species expanded continuously from Southern Asia to India and Eastern Asia, reaching as far as Japan (Fig. 2).

During the Oligocene and Miocene the uplift progressed, causing the extension of the Tibetan Plateau (Harrison et al. 1992; Mulch \& Chamberlain 2006). The start of the uplift of the northern Tibetan Plateau occurred at about 30 Ma BP (Sun \& Wang 2005) or slightly earlier (Wang et al. 2012b). Then, the eastern parts of the Tibetan Plateau likely reached an elevation comparable to the present-day elevation in the Mid to Late Miocene (from 15 to $5 \mathrm{Ma}$ ) (Axelrod 1997; Currie et al. 2005; Jacques et al. 2011; Spicer et al. 2003; Tapponnier et al. 2001; Valdiya 1999; Zhang et al. 2013). The southeastern edge of the Tibetan Plateau, the Hengduan mountain range, experienced rapid uplift only after the Miocene (5.33 Ma), reaching a peak elevation shortly before the Late Pliocene (5.33 - 2.66 Ma) (Li \& Fang 1999; Mulch \& Chamberlain 2006; Sun et al. 2011; Zheng et al. 2000), which separated several major rivers that ran in parallel (the Yangtze, Mekong, and Salween valleys) (Clark et al. 2004). This series of rapid Tibetan Plateau uplifts dramatically changed the terrain and landform in this area, which resulted in speciation, especially in animal groups (Che et al. 2010; Deng et al. 2011; Gao et al. 2013; Jabbour \& Renner 2012; Lei et al. 2014; Li et al. 2013; Shi et al. 1999; Tietze \& Borthakur 2012; Tietze et 
255 al. 2013; Tu et al. 2010; Wang et al. 2009; Zhang et al. 2006). Zhang et al. (2006) found that the

256 origin and phylogenetic divergence of the Hynobiidae had a correlation to the uplift of the

257 Tibetan Plateau (Zhang et al. 2006). The phylogenetic history of Paini (Anura: Dicroglossidae)

258 illuminates a critical aspect of the timing of geological events, especially for the uplift of the

259 Tibetan Plateau (Che et al. 2010). On the other hand, the Tibetan Plateau and its adjacent

260 mountain ranges acted as an orographic barrier to atmospheric circulation in Asia and

261 consequently contributed to the formation of the Asian monsoon system, which was one of the

262 major climatic changes in this region (Early Miocene, $24 \mathrm{Ma}$ ) due to the Tibetan Plateau's

263 considerable size and altitude (Guo et al. 2008; Kutzbach et al. 1993; Liu \& Yin 2002; Ruddiman

264 \& Kutzbach 1991; Song et al. 2010; Sun \& Wang 2005; Tang et al. 2013; Zhisheng et al. 2001).

265 In the following millions of years, the East Asian monsoon intensified three times $(\sim 15 \mathrm{Ma}, \sim 8$

266 Ma and 4 - 3 Ma) (An et al. 2001; Jacques et al. 2011; Molnar et al. 2010; Song et al. 2010; Sun

267 \& Wang 2005; Valdiya 1999; Wan et al. 2007; Zhisheng et al. 2001). The development of the

268 Asian monsoon system directly gave birth to the warm and humid climate in the south of China

269 (Sun \& Wang 2005), which was maybe favorable for the geographical spread and speciation of

270 amphibians (Che et al. 2010; Thorn \& Raffaèlli 2001; Wu et al. 2013; Zhang et al. 2006). In

271 addition, the climate oscillations that began about 2.8 million years ago, in the Late Pliocene

272 (Deng et al. 2011), also provided the chance for diversification and speciation of many species

273 (Zhang et al. 2000), such as birds (Lei et al. 2014), the Tibetan woolly rhino (Coelodonta

thibetana) (Deng et al. 2011) and stream-dwelling frog (Feirana quadranus) (Wang et al. 2012a).

Molecular dating suggested that the TMRC of Clade A and Clade B was during the Oligocene 
276 (22.44 Ma - 32.17 Ma) (Fig. 3, Table 1). At same time, ancestral area reconstructions supported

277 Southeast Asia (W) as the ancestral area of Rhacophorus and the dispersal events happened from

278 ancestral area of Clade A and Clade B (Fig. 2, node b). In addition, the land and sea in the Indo-

279 Australian Archipelago changed greatly during this period (Lohman et al. 2011), which may

280 promote the dispersal events from Southeast Asia. In Clade A, the time of the split of subgroups

281 was estimated from 14.09 to $5.33 \mathrm{Ma}$ (Table 1). In addition, the time of most nodes in Clade B

282 also occurred during this period (Fig. 3). Based on the LTT plot analysis, there were two

283 increased diversification rate periods (14 - $12 \mathrm{Ma}, 10-4 \mathrm{Ma})$ in Rhacophorus (Fig. 4). The

284 series of Tibetan Plateau rapid uplifts (from 15 to $2.66 \mathrm{Ma}$ ) dramatically changed the landscape,

285 which resulted in the diversification of species or speciation in this area (Che et al. 2010; Deng et

286 al. 2011; Gao et al. 2013; Jabbour \& Renner 2012; Lei et al. 2014; Li et al. 2013; Shi et al. 1999;

287 Tietze \& Borthakur 2012; Tietze et al. 2013; Tu et al. 2010; Wang et al. 2009; Zhang et al. 2006)

288 and the biotic interchange between the Indian subcontinent and mainland Asia (Klaus et al.

289 2016). In addition, the intensified East Asian monsoon ( 15 Ma, 8 Ma and $4-3 \mathrm{Ma})$ directly

290 gave birth to the warm and humid climate in the south of China, which was favorable for the

291 geographical spread and speciation of amphibians (Che et al. 2010; Thorn \& Raffaèlli 2001; Wu

292 et al. 2013; Zhang et al. 2006). Obviously, the diversification events in Rhacophorus were in line

293 with the time frame of the orogenic movement and climatic histories, especially the staged rapid

294 uplift of the Tibetan Plateau and the enhanced Asian monsoon system (Figs. 2 and 3). Therefore,

295 we think that the diversification and speciation events in Clade A and Clade B, are related to the

296 staged uplift of the Tibetan Plateau and the subsequent chain-reaction events, such as the 
297

298

299

300

301

302

303

304

305

306

307

308

309

310

311

312

313

establishment of the Asian monsoon system, which facilitated the radiations and speciation of amphibians (Che et al. 2010; Thorn \& Raffaèlli 2001; Wu et al. 2013; Zhang et al. 2006).

Overall, the evolutionary history of Rhacophorus originated approx $30 \mathrm{Ma}$ Bp (Oligocene).

Basically, it is the dispersal process from its ancestral area, Southeast Asia, toward India and

East Asia. During the process, Rhacophorus diversified by multiple factors, such as geographic shifts, the staged rapid rises of the Tibetan Plateau with parallel climatic changes, the reinforcement of the Asian monsoons (15 Ma, $8 \mathrm{Ma}$ and 4-3 Ma) and alternating glacialinterglacial oscillations.

\section{ACKNOWLEDGEMENTS}

We thank Wenliang Zhou, Zhonglou Sun, Zhaojie Peng and Xiaonan Sun for their help in sample collecting, John Bailey (Department of Genetics, University of Leicester) and Martin Burrows for input concerning the quality of the writing as regards the English language, Jiatang Li (Chengdu Institute of Biology, Chinese Academy of Sciences) for the study design, and thank the reviewers (Nguyen Tao, Gururaja Kotambylu Vasudeva and an anonymous reviewer) for their suggestions. We thank Tianma National Nature Reserve in Anhui Province for the investigation project and the sample collection. 


\section{REFERENCES}

316 An ZS, Kutzbach JE, Prell WL, and Porter SC. 2001. Evolution of Asian monsoons and phased uplift of the Himalaya-Tibetan plateau since Late Miocene times. Nature 411:62-66.

318

319

320

321

322

323

324

325

326

327

328

329

330

331

332

333

334

Antonelli A, and Sanmartín I. 2011. Why are there so many plant species in the Neotropics? Taxon 60:403-414.

Avise JC. 2000. Phylogeography: the history and formation of species. Boston: Harvard University Press.

Axelrod DI. 1997. Paleoelevation estimated from Tertiary floras. Int Geol Rev 39:1124-1133.

Benton MJ. 2009. The Red Queen and the Court Jester: species diversity and the role of biotic and abiotic factors through time. Science 323:728-732.

Biju SD, Kamei RG, Mahony S, Thomas A, Garg S, Sircar G, and Suyesh R. 2013. Taxonomic review of the tree frog genus Rhacophorus from the Western Ghats, India (Anura: Rhacophoridae), with description of ontogenetic colour changes and reproductive behavior. Zootaxa 3636:257-289.

Bird MI, Taylor D, and Hunt C. 2005. Palaeoenvironments of insular Southeast Asia during the Last Glacial Period: a savanna corridor in Sundaland? Quaternary Sci Rev 24:2228-2242.

Bossuyt F, and Milinkovitch MC. 2000. Convergent adaptive radiations in Madagascan and Asian ranid frogs reveal covariation between larval and adult traits. P Natl Acad Sci 97:6585-6590.

Che J, Zhou WW, Hu JS, Yan F, Papenfuss TJ, Wake DB, and Zhang YP. 2010. Spiny frogs 
335

336

337

338

339

340

341

342

343

344

345

346

347

348

349

350

351

352

353

354

355

(Paini) illuminate the history of the Himalayan region and Southeast Asia. P Natl Acad Sci 107:13765-13770.

Clark MK, Schoenbohm LM, Royden LH, Whipple KX, Burchfiel BC, Zhang X, Tang W, Wang E, and Chen L. 2004. Surface uplift, tectonics, and erosion of eastern Tibet from large - scale drainage patterns. Tectonics 23:1-20.

Currie BS, Rowley DB, and Tabor NJ. 2005. Middle Miocene paleoaltimetry of southern Tibet: implications for the role of mantle thickening and delamination in the Himalayan orogen. Geology 33:181-184.

Deng T, Wang XM, Fortelius M, Li Q, Wang Y, Tseng ZJ, Takeuchi GT, Saylor JE, Säilä LK, and Xie GP. 2011. Out of Tibet: Pliocene woolly rhino suggests high-plateau origin of Ice Age megaherbivores. Science 333:1285-1288.

Drummond AJ, Suchard MA, Xie D, and Rambaut A. 2012. Bayesian phylogenetics with BEAUti and the BEAST 1.7. Mol Biol Evol 29:1969-1973.

Esselstyn JA, Timm RM, and Brown RM. 2009. Do geological or climatic processes drive speciation in dynamic archipelagos? The tempo and mode of diversification in Southeast Asian shrews. Evolution 63:2595-2610.

Evans BJ, Brown RM, McGuire JA, Supriatna J, Andayani N, Diesmos A, Iskandar D, Melnick DJ, and Cannatella DC. 2003. Phylogenetics of fanged frogs: testing biogeographical hypotheses at the interface of the Asian and Australian faunal zones. Syst Biol 52:794819.

Favre A, Päckert M, Pauls SU, Jähnig SC, Uhl D, Michalak I, and Muellner - Riehl AN. 2015. 
356

357

358

359

360

361

362

363

364

365

366

367

368

369

370

371

372

373

374

375

376

The role of the uplift of the Qinghai - Tibetan Plateau for the evolution of Tibetan biotas. Biol Rev 90:236-253.

Frankham R, Briscoe DA, and Ballou JD. 2002. Introduction to conservation genetics. Oxford: Cambridge University Press.

Frost DR. 2016. Amphibian Species of the World: an Online Reference. Version 6.0 (27 May, 2016). American Museum of Natural History, New York, USA.

Gao YD, Harris AJ, Zhou SD, and He XJ. 2013. Evolutionary events in Lilium (including Nomocharis, Liliaceae) are temporally correlated with orogenies of the Q-T plateau and the Hengduan Mountains. Mol Phylogenet Evol 68:443-460.

Guo XG, Dai X, Chen D, Papenfuss TJ, Ananjeva NB, Melnikov DA, and Wang YZ. 2011. Phylogeny and divergence times of some racerunner lizards (Lacertidae: Eremias) inferred from mitochondrial 16S rRNA gene segments. Mol Phylogenet Evolution 61:400-412.

Guo ZT, Sun B, Zhang ZS, Peng SZ, Xiao GQ, Ge JY, Hao QZ, Qiao YS, Liang MY, and Liu JF. 2008. A major reorganization of Asian climate by the early Miocene. Clim Past 4:153174.

Hall R. 1996. Reconstructing Cenozoic SE Asia. Pages 153-184 in Tectonic evolution of southeast Asia (R. Hall and D. Blundell, eds.). London: Geological Society of London Special Publication.

Hall R. 1998. The plate tectonics of Cenozoic SE Asia and the distribution of land and sea. Pages 99-131 in Biogeography and geological evolution of SE Asia (R. Hall and J. D. 
Holloway, eds.). Leiden: Backhuys Publishers.

378

379

380

381

382

383

384

385

386

387

388

389

390

391

392

393

394

395

396

397

Hall R. 2002. Cenozoic geological and plate tectonic evolution of SE Asia and the SW Pacific: computer-based reconstructions, model and animations. $J$ Asian Earth Sci 20:353-431.

Harrison TM, Copeland P, Kidd WSF, and Yin AN. 1992. Raising tibet. Science 255:1663-1670.

Heaney LR. 1985. Zoogeographic evidence for middle and late Pleistocene land bridges to the Philippine Islands. Mod Quat Res SE Asia 9:127-144.

Heaney LR. 1986. Biogeography of mammals in SE Asia: estimates of rates of colonization, extinction and speciation. Biol J Linn Soc 28:127-165.

Huelsenbeck JP, and Ronquist F. 2005. MrBayes. Version 3.1. 2. $<$ http://mrbayes.scs.fsu.edu/download.php $>$.

Jabbour F, and Renner SS. 2012. A phylogeny of Delphinieae (Ranunculaceae) shows that Aconitum is nested within Delphinium and that Late Miocene transitions to long life cycles in the Himalayas and Southwest China coincide with bursts in diversification. Mol Phylogenet Evol 62:928-942.

Jacques FMB, Guo SX, Su T, Xing YW, Huang YJ, Liu YS, Ferguson DK, and Zhou ZK. 2011. Quantitative reconstruction of the Late Miocene monsoon climates of southwest China: a case study of the Lincang flora from Yunnan Province. Palaeogeogr Palaeocl 304:318327.

Jansa SA, Barker FK, and Heaney LR. 2006. The pattern and timing of diversification of Philippine endemic rodents: evidence from mitochondrial and nuclear gene sequences. Syst Biol 55:73-88. 
398

399

400

401

402

403

404

405

406

407

408

409

410

411

412

413

414

415

416

417

418

Klaus S, Morley RJ, Plath M, Zhang YP, and Li JT. 2016. Biotic interchange between the Indian subcontinent and mainland Asia through time. Nat Commun 7:12132.

Kutzbach JE, Prell WL, and Ruddiman WF. 1993. Sensitivity of Eurasian climate to surface uplift of the Tibetan Plateau. J Geol 101:177-190.

Lei FM, Qu YH, and Song G. 2014. Species diversification and phylogeographical patterns of birds in response to the uplift of the Qinghai-Tibet Plateau and Quaternary glaciations. Current Zoology 60:149-161.

Li JJ, and Fang XM. 1999. Uplift of the Tibetan Plateau and environmental changes. Chinese Sci Bull 44:2117-2124.

Li JT, Che J, Murphy RW, Zhao H, Zhao EM, Rao DQ, and Zhang YP. 2009. Evolution of reproduction in the Rhacophoridae (Amphibia: Anura) inferred from a phylogenetic analysis of five nuclear and three mitochondrial genes. Mol Phylogenet Evol 53:509-522.

Li JT, Li Y, Klaus S, Rao DQ, Hillis DM, and Zhang YP. 2013. Diversification of rhacophorid frogs provides evidence for accelerated faunal exchange between India and Eurasia during the Oligocene. Proceed Nat Acad Sci 110:3441-3446.

Li JT, Li Y, Murphy RW, Rao DQ, and Zhang YP. 2012a. Phylogenetic resolution and systematics of the Asian tree frogs, Rhacophorus (Rhacophoridae, Amphibia). Zool Scr 41:557-570.

Li JT, Liu J, Chen YY, Wu JW, Murphy RW, Zhao EM, Wang YZ, and Zhang YP. 2012 b. Molecular phylogeny of treefrogs in the Rhacophorus dugritei species complex (Anura: Rhacophoridae), with descriptions of two new species. Zool J Linn Soc 165:143-162. 
419 Liu XD, and Yin ZY. 2002. Sensitivity of East Asian monsoon climate to the uplift of the Tibetan Plateau. Palaeogeogra Palaeocl 183:223-245.

421

422

423

424

425

426

427

428

429

430

431

432

433

434

435

436

437

438

439

Lohman DJ, Bruyn MD, Page T, Rintelen KV, Hall R, Ng PKL, Shih HT, Carvalho GR, and Rintelen TV. 2011. Biogeography of the Indo-Australian Archipelago. Annu Rev Ecol Evol S 42:205-226.

Molnar P, Boos WR, and Battisti DS. 2010. Orographic controls on climate and paleoclimate of Asia: thermal and mechanical roles for the Tibetan Plateau. Annu Rev Earth Pl Sc 38:77.

Mulch A, and Chamberlain CP. 2006. Earth science: The rise and growth of Tibet. Nature 439:670-671.

Myers N, Mittermeier RA, Mittermeier CG, Da Fonseca GAB, and Kent J. 2000. Biodiversity hotspots for conservation priorities. Nature 403:853-858.

Nee S, May RM, and Harvey PH. 1994. The reconstructed evolutionary process. Philosophical Transactions of the Royal Society B: Biological Sciences 344:305-311.

Nylander JAA. 2003. MrModeltest 1.0 b. a simplified version of David Posada's ÔÔModeltest 3.06 “. Uppsala, Sweden: Department of Systematic Zoology.

Orlov NL, Poyarkov NA, Vassilieva AB, Ananjeva NB, Nguyen T, Sang N, and Geissler P. 2012. Taxonomic notes on Rhacophorid frogs (Rhacophorinae: Rhacophoridae: Anura) of southern part of Annamite Mountains (Truong Son, Vietnam), with description of three new species. Russ J Herpetol 19:23-64.

Pan T, Zhang YN, Wang H, Wu J, Kang X, Qian LF, Li K, Zhang Y, Chen JY, Rao DQ, Jiang JP, and Zhang BW. 2017. A New Species of the Genus Rhacophorus (Anura: 
441

442

443

444

445

446

447

448

449

450

451

452

453

454

455

456

457

458

459

460

Qiang XK, Li ZX, Powell CMA, and Zheng HB. 2001. Magnetostratigraphic record of the Late Miocene onset of the East Asian monsoon, and Pliocene uplift of northern Tibet. Earth Planet Sc Lett 187:83-93.

Rambaut A. 2009. FigTree version 1.3. 1. Computer program distributed by the author<http://tree bio ed ac uk/software/figtree/[accessed January 4, 2011]>.

Rambaut A, and Drummond AJ. 2007. Tracer. Version 1.5.

Rambaut A, and Drummond AJ. 2010. TreeAnnotator version 1.6. 1.

Ronquist F, and Huelsenbeck JP. 2003. MrBayes3: Bayesian phylogenetic inference undermixed models. Bioinformatics:1572-1574.

Ruddiman WF, and Kutzbach JE. 1991. Plateau uplift and climatic change. Sci Am 264:66-75.

Sambrook J, Fritsch EF, and Maniatis T. 1989. Molecular cloning. New York: Cold spring harbor laboratory press.

Schmitt LH, Kitchener DJ, and How RA. 1995. A genetic perspective of mammalian variation and evolution in the Indonesian Archipelago: biogeographic correlates in the fruit bat genus Cynopterus. Evolution 49:399-412.

Shi YF, Li JJ, Li BY, Yao TD, Wang SM, Li SJ, Cui ZJ, Wang FB, Pan BT, Fang XM, and Zhang QS. 1999. Uplift of the Qinghai-Tibetan plateau and East Asia environmental change during late Cenozoic. Acta Geographical Sinica 54:10-20.

Song JH, Kang HS, Byun YH, and Hong SY. 2010. Effects of the Tibetan Plateau on the Asian summer monsoon: a numerical case study using a regional climate model. Int J Climatol 
30:743-759.

462

463

464

465

466

467

468

469

470

471

472

473

474

475

476

477

478

479

480

481

Spicer RA, Harris NBW, Widdowson M, Herman AB, Guo SX, Valdes PJ, Wolfe JA, and Kelley SP. 2003. Constant elevation of southern Tibet over the past 15 million years. Nature 421:622-624.

Stamatakis A. 2014. RAxML version 8: a tool for phylogenetic analysis and post-analysis of large phylogenies. Bioinformatics 30:1312-1313.

Sun BN, Wu JY, Liu YS, Ding ST, Li XC, Xie SP, Yan DF, and Lin ZC. 2011. Reconstructing Neogene vegetation and climates to infer tectonic uplift in western Yunnan, China. Palaeogeogra Palaeocl 304:328-336.

Sun XG, and Wang PX. 2005. How old is the Asian monsoon system?-Palaeobotanical records from China. Palaeogeogra Palaeocl 222:181-222.

Tang H, Micheels A, Eronen JT, Ahrens B, and Fortelius M. 2013. Asynchronous responses of East Asian and Indian summer monsoons to mountain uplift shown by regional climate modelling experiments. Clim Dynam 40:1531-1549.

Tapponnier P, Xu ZQ, Roger F, Meyer B, Arnaud N, Wittlinger G, and Yang JS. 2001. Oblique stepwise rise and growth of the Tibet Plateau. Science 294:1671-1677.

Thompson JD, Gibson TJ, Plewniak F, Jeanmougin F, and Higgins DG. 1997. The CLUSTAL X windows interface: flexible strategies for multiple sequence alignment aided by quality analysis tools. Nucleic Acids Res 25:4876-4882.

Thorn R, and Raffaèlli J. 2001. Les salamandres de l'ancien monde. Paris: Editions Boubée. Tietze DT, and Borthakur U. 2012. Historical biogeography of tits (Aves: Paridae, Remizidae). 
483

484

485

486

487

488

489

490

491

492

493

494

495

496

497

498

499

500

501

502

Tietze DT, Päckert M, Martens J, Lehmann H, and Sun YH. 2013. Complete phylogeny and historical biogeography of true rosefinches (Aves: Carpodacus). Zool J Linn Soc 169:215-234.

Tu T, Volis S, Dillon MO, Sun H, and Wen J. 2010. Dispersals of Hyoscyameae and Mandragoreae (Solanaceae) from the New World to Eurasia in the early Miocene and their biogeographic diversification within Eurasia. Mol Phylogenet Evol 57:1226-1237.

Valdiya KS. 1999. Rising Himalaya: Advent and intensification of monsoon. Curr Sci 76:514524.

van der Meijden A, Vences M, Hoegg S, Boistel R, Channing A, and Meyer A. 2007. Nuclear gene phylogeny of narrow-mouthed toads (Family: Microhylidae) and a discussion of competing hypotheses concerning their biogeographical origins. Mol Phylogenet Evol 44:1017-1030.

Venditti C, Meade A, and Pagel M. 2010. Phylogenies reveal new interpretation of speciation and the Red Queen. Nature 463:349-352.

Vieites DR, Min M-S, and Wake DB. 2007. Rapid diversification and dispersal during periods of global warming by plethodontid salamanders. Proceed Nat Acad Sci 104:19903-19907.

Vijayakumar SP, Menezes RC, Jayarajan A, and Shanker K. 2016. Glaciations, gradients, and geography: multiple drivers of diversification of bush frogs in the Western Ghats Escarpment. P Roy Soc B 283.

Voris HK. 2000. Maps of Pleistocene sea levels in Southeast Asia: shorelines, river systems and 
time durations. J Biogeogr 27:1153-1167.

504

505

506

507

508

509

510

511

512

513

514

515

516

517

518

519

520

521

522

523

Wallace AR. 1860. On the zoological geography of the Malay Archipelago. Proc Linn Soc 4:172-184.

Wan SM, Li AC, Clift PD, and Stuut JBW. 2007. Development of the East Asian monsoon: mineralogical and sedimentologic records in the northern South China Sea since 20 Ma. Palaeogeogra Palaeocl 254:561-582.

Wang B, Jiang JP, Xie F, and Li C. 2012a. Postglacial colonization of the Qinling Mountains: phylogeography of the Swelled Vent frog (Feirana quadranus). PloS one 7:1-14.

Wang YD, Zheng JJ, Zhang WL, Li SY, Liu XW, Yang X, and Liu YH. 2012b. Cenozoic uplift of the Tibetan Plateau: Evidence from the tectonic-sedimentary evolution of the western Qaidam Basin. Geoscience Frontiers 3:175-187.

Wang YJ, Susanna A, Von Raab-Straube E, Milne R, and Liu JQ. 2009. Island - like radiation of Saussurea (Asteraceae: Cardueae) triggered by uplifts of the Qinghai-Tibetan Plateau. Biol J Linn Soc 97:893-903.

Wiens JJ, Fetzner JW, Parkinson CL, and Reeder TW. 2005. Hylid frog phylogeny and sampling strategies for speciose clades. Syst Biol 54:778-807.

Wu YK, Wang YZ, Jiang K, and Hanken J. 2013. Significance of pre-Quaternary climate change for montane species diversity: insights from Asian salamanders (Salamandridae: Pachytriton). Mol Phylogenet Evol 66:380-390.

Yang SJ, Dong HL, and Lei FM. 2009. Phylogeography of regional fauna on the Tibetan Plateau: a review. Prog Nat Sci 19:789-799. 
524 Yu Y, Harris AJ, Blair C, and He XJ. 2015. RASP (Reconstruct Ancestral State in Phylogenies): a tool for historical biogeography. Mol Phylogenet Evol 87:46-49.

526

527

528

529

530

531

532

533

534

535

536

537

538

539

540

541

542

543

544

Zhang DF, Fengquan L, and Jianmin B. 2000. Eco-environmental effects of the Qinghai-Tibet Plateau uplift during the Quaternary in China. Environ Geol 39:1352-1358.

Zhang P, Chen YQ, Zhou H, Liu YF, Wang XL, Papenfuss TJ, Wake DB, and Qu LH. 2006. Phylogeny, evolution, and biogeography of Asiatic Salamanders (Hynobiidae). P Nat Acad Sci 103:7360-7365. DOI 10.1073/pnas.0602325103

Zhang WL, Fang XM, Song CH, Appel E, Yan MD, and Wang YD. 2013. Late Neogene magnetostratigraphy in the western Qaidam Basin (NE Tibetan Plateau) and its constraints on active tectonic uplift and progressive evolution of growth strata. Tectonophysics 599:107-116.

Zheng HB, Powell CMA, An ZS, Zhou J, and Dong GG. 2000. Pliocene uplift of the northern Tibetan Plateau. Geology 28:715-718.

Zhisheng A, Kutzbach JE, Prell WL, and Porter SC. 2001. Evolution of Asian monsoons and phased uplift of the Himalaya-Tibetan plateau since Late Miocene times. Nature 411:6266. 


\section{Figure 1 (on next page)}

Sample sites of Rhacophorus species used in this study. 


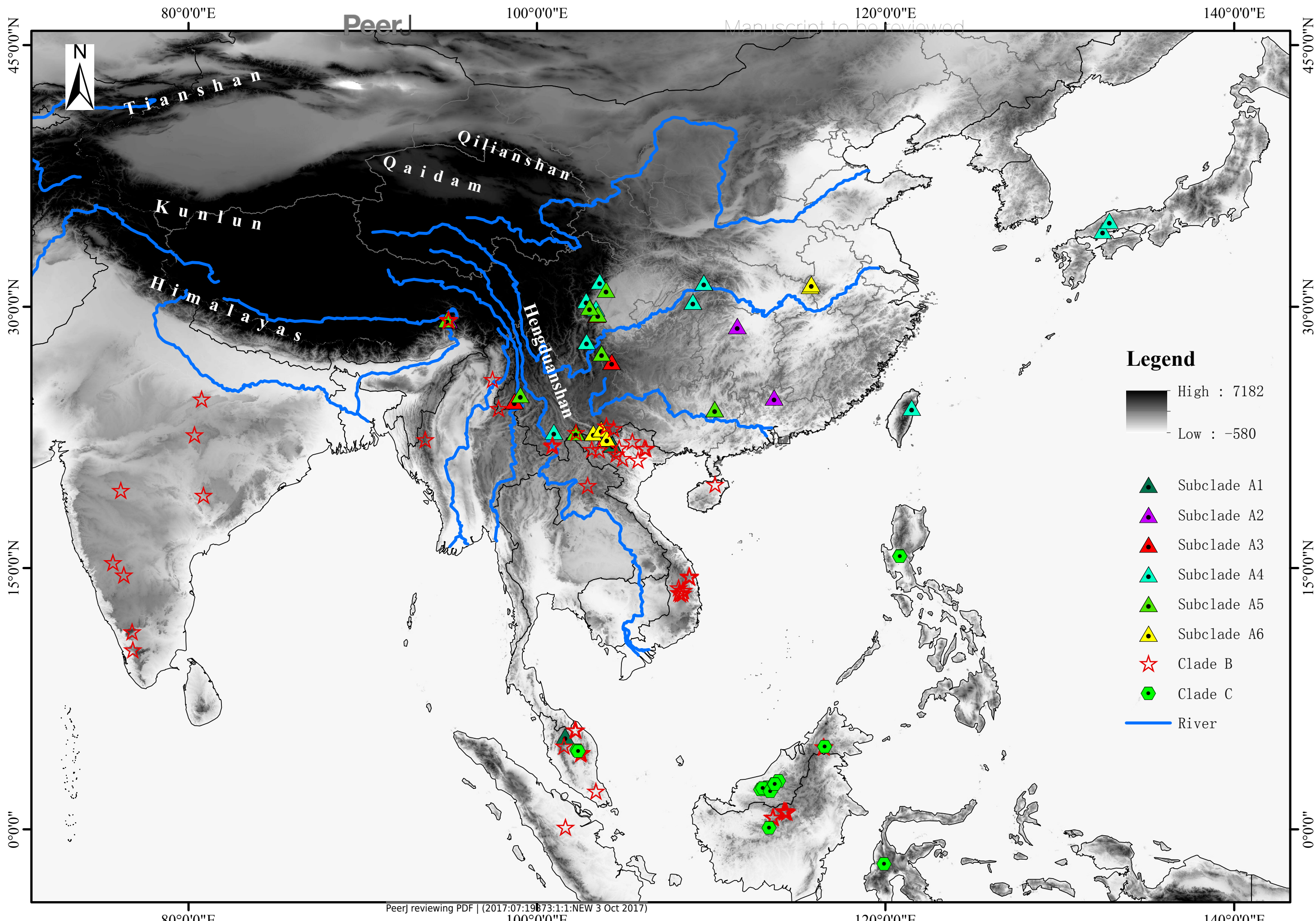

$80^{\circ} 0^{\prime} 0^{\prime \prime} \mathrm{E}$ 


\section{Figure 2 (on next page)}

Chronogram and ancestral area reconstructions of Rhacophorus with outgroup species, Polypedates megacephalus and Spinomantis peraccae based on Dataset 1.

Branches in the tree are proportional to absolute ages (Ma). Node charts showed the relative probabilities of alternative ancestral distributions obtained by integrating the statistical dispersal-vicariance analysis (S-DIVA; above branches) and a Bayesian Binary MCMC method (BBM; below branches), and the first two areas with highest probability are shown corresponding to their relative probability on the area of one circle. Areas are divided for reconstructing ancestral areas. (W) Southeast Asia, including the Indochinese Peninsula, Sundaland, and the south margin of the Tibetan Plateau; $(X)$ Hengduan mountains and the mountains around the Sichuan Basin; (Y) South China and Japan; (Z) India. 


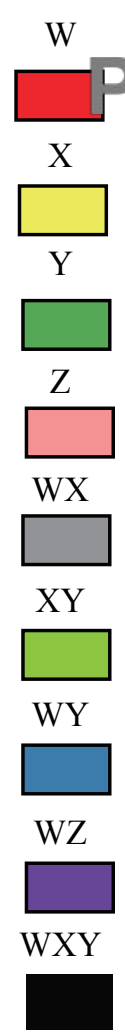

Dispersal

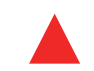

Vicariance

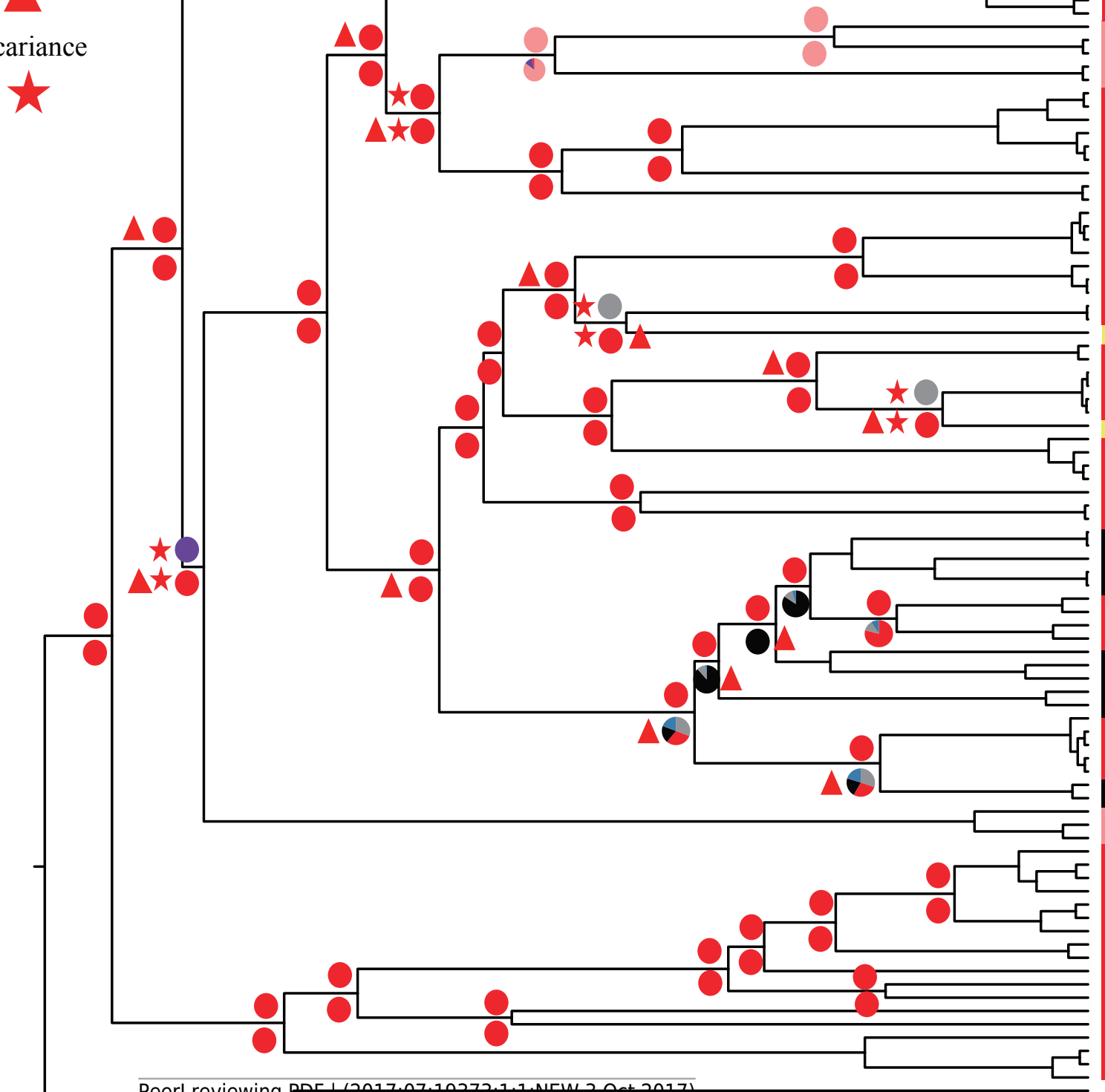

Peer) reviewing_POF | (2017:07:19373:1:1:NEW 3 Oet 2017)
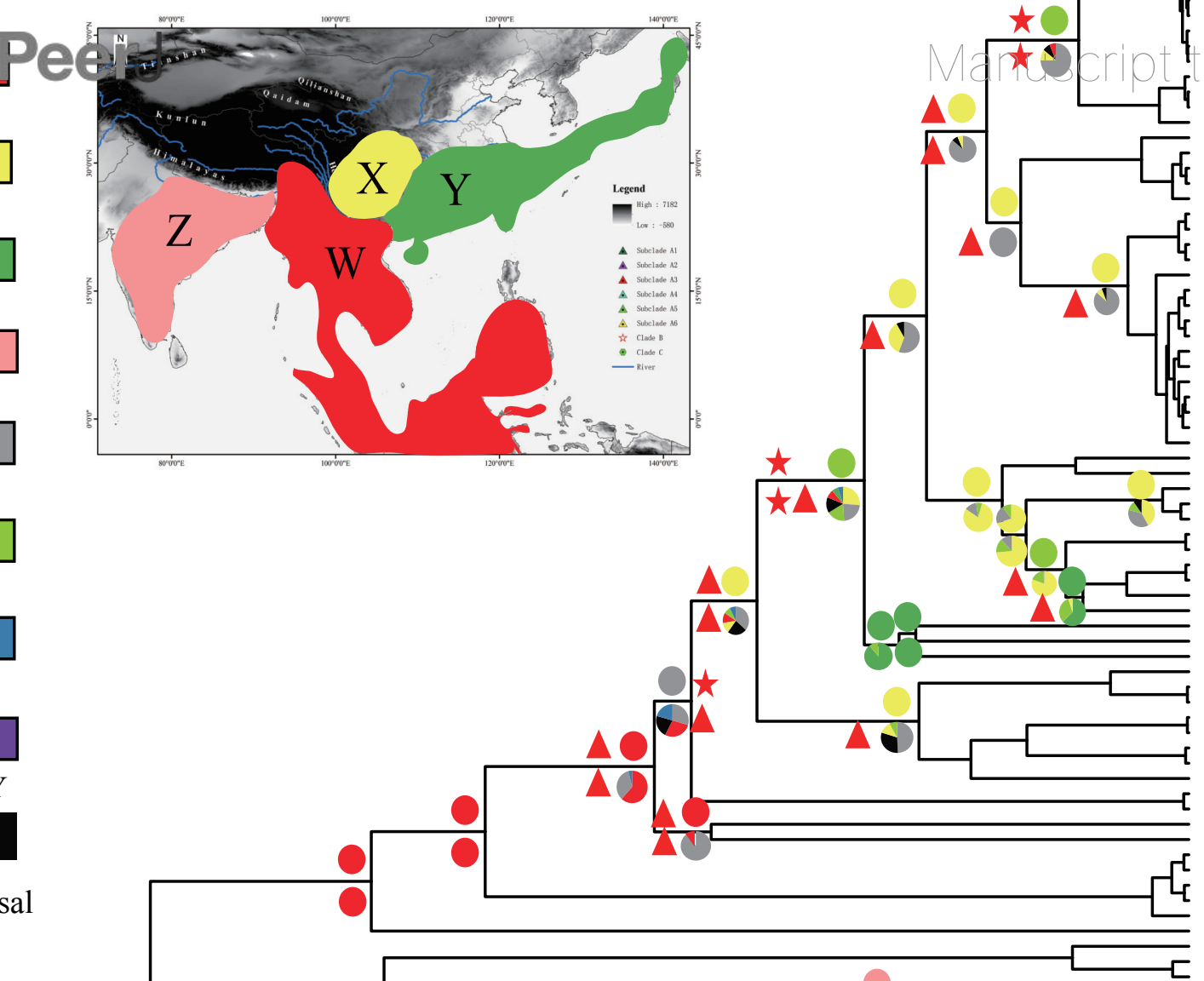

舟
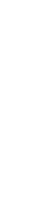


\section{Figure 3 (on next page)}

Biogeographical history of Rhacophorus.

(i) Time-calibrated phylogeny of the genus Rhacophorus inferred from the mitochondrial dataset with an outgroup species, Polypedates megacephalus and Spinomantis peraccae. The light-blue bars through the nodes indicate $95 \%$ credibility intervals. Detailed time estimates for nodes with letter labels are given in Table 1; ( ii ) Climatic sequence of events including a global average delt ${ }^{18} \mathrm{O}$ curve (right-hand axis) derived from benthic foraminifera which mirrors the major global temperature trends from the Paleocene to the Pleistocene (red line) [modified from Zachos et al. (2001), Zachos et al. (2008) and Favre et al. (2015)]. The establishment of ice sheets in the Northern Hemisphere is indicated by grey to black bars on top. The onset and development of the monsoon is symbolised by a blue polygon and its intensification by grey bars ( I , II and III ) (Wan et al. 2007; Jacques et al. 2011). The climate oscillations during the Quaternary are represented by a grey bar ( IV ) (Deng et al. 2011); ( iii ) Geological sequences of events are related to the diversification of Rhacophorus including the reconstructions historical land and sea in Southeast Asia and a graphical representation of the extent of the uplift of the TP through time. (1) and (2) show two Cenozoic reconstructions of land and sea in the Indo-Australian Archipelago [modified from Lohman et al. (2011)]. Red shading in (3) and (4) indicates the portion of the TP that had achieved altitudes comparable to the present day for each given time [modified from Mulch \& Chamberlain, (2006) and Favre et al. (2015)]. 



\section{Figure 4 (on next page)}

Visualization of diversification rate shifts of Rhacophorus.

(A) Lineage-through-time plot (logarithmic scale) and 95\% confidence intervals of lineage

diversification; (B) Cumulative curve of diversification rate per million years. The dashed line represents the period of rapid diversification in Rhacophorus. 


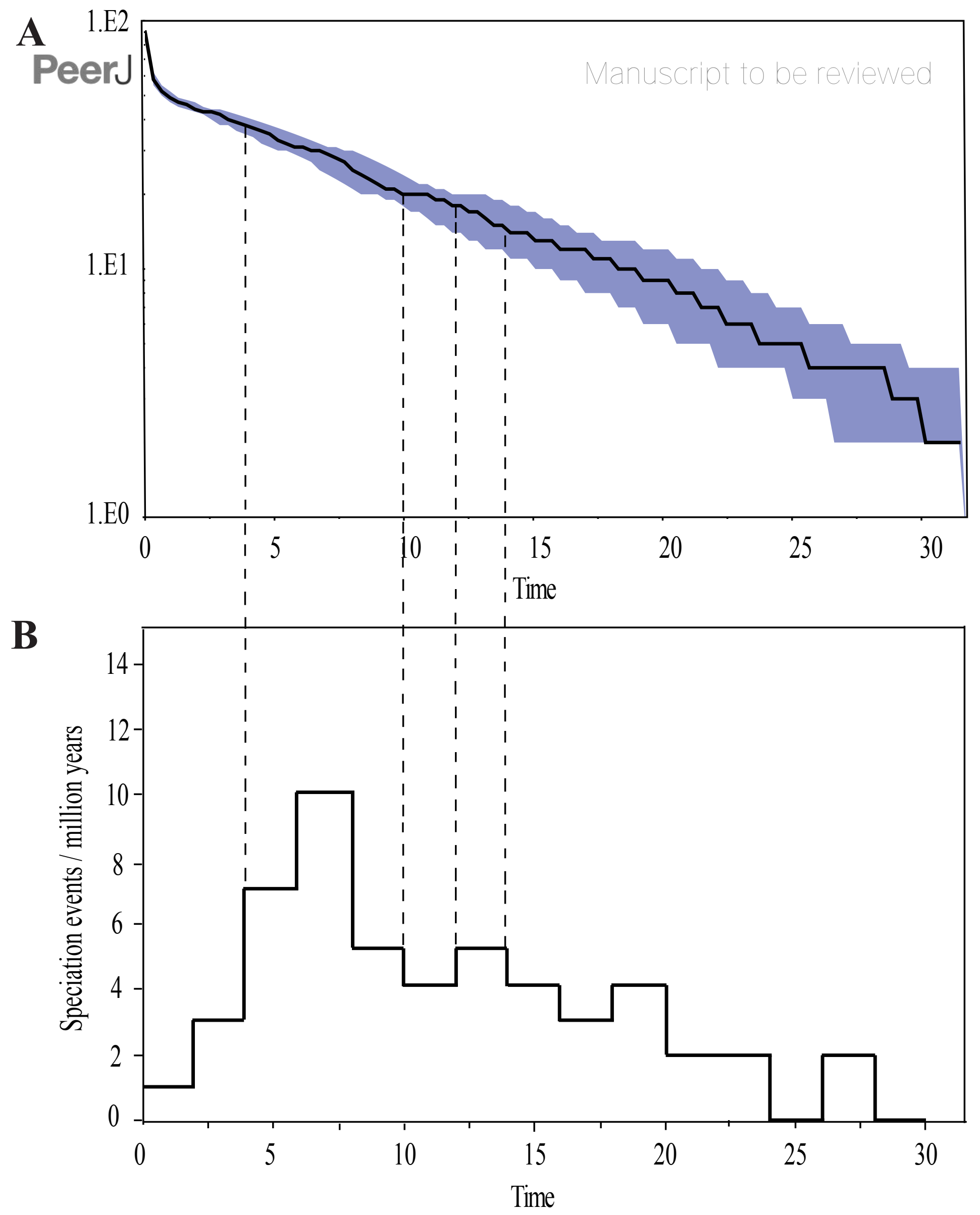




\section{Table $\mathbf{1}$ (on next page)}

Detailed results of molecular dating using BEAST 1.7.4, and the calibration points.

Labels for nodes correspond to Fig. 3. Unit: one million years. The abbreviation of time to most recent common ancestor is TMRC. 
1 Table 1. Detailed results of molecular dating using BEAST 1.7.4, and the calibration points.

2 Labels for nodes correspond to Fig. 3. Unit: one million years. The abbreviation of time to most

3 recent common ancestor is TMRC.

\begin{tabular}{|c|c|c|c|}
\hline Node & TMRC & Mean $(95 \%)$ & $\begin{array}{c}\text { Mean(95\%) } \\
\text { (Li et al. } 2013)\end{array}$ \\
\hline Root & --- & $\begin{array}{c}33.27(25.11- \\
40.20)\end{array}$ & $36.5(31.2-40.9)$ \\
\hline $\mathrm{a}$ & Clade A, B, C & $\begin{array}{c}29.51(25.34- \\
34.07)\end{array}$ & $30.6(25.2-34.7)$ \\
\hline $\mathrm{b}$ & Clade A, B & $\begin{array}{c}27.38(22.44- \\
32.17)\end{array}$ & --- \\
\hline $\mathrm{c}$ & Clade A & $\begin{array}{c}21.56(17.92- \\
25.22)\end{array}$ & $21.6(17.5-25.1)$ \\
\hline$d$ & Groups A2-A6 & $\begin{array}{c}14.09(10.96- \\
17.41)\end{array}$ & --- \\
\hline e & Groups A3-A6 & $11.39(8.89-14.16)$ & --- \\
\hline $\mathrm{f}$ & Groups A4-A6 & $8.56(6.43-10.88)$ & --- \\
\hline g & Groups A5, A6 & $5.33(3.92-6.99)$ & --- \\
\hline $\mathrm{h}$ & Ggroup A6 & $2.9(1.78-4.29)$ & --- \\
\hline $\mathrm{i}$ & --- & $8.4(6.43-10.29)$ & $8.6(5.5-9.8)$ \\
\hline
\end{tabular}

